\title{
Ordu ilinde bulunan bazı anıt ağaçların genel özellikleri*
}

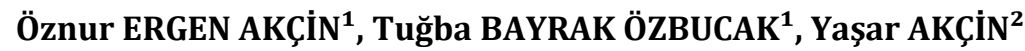

${ }^{1}$ Ordu Üniversitesi Fen-Edebiyat Fakültesi, Moleküler Biyoloji ve Genetik Bölümü, Ordu

${ }^{2}$ Ordu Üniversitesi Fen Bilimleri Enstitüsü, Bahçe Bitkileri Anabilim Dalı, Ordu

*Bu çalışma 22. Ulusal Biyoloji Kongresinde poster bildiri olarak sunulmuş kongre kitapçığında kısa özet olarak basılmıștır.

Alınıș tarihi: 16 Nisan 2018, Kabul tarihi: 30 Ekim 2018

Sorumlu yazar: Öznur ERGEN AKÇIN, e-posta: oakcin@gmail.com

Öz

$\mathrm{Bu}$ çalışmada Ordu ili ve çevresinde bulunan ve tabiat varlığı olarak tescil edilmiş 15 anıt ağaç bulundukları habitatlarda incelenmiş ve özellikleri hakkında bilgiler verilmiștir. Anıt ağaçların tür isimleri, familya isimleri, tahmini yaşları, çapları, boyları, ilk dallanma yüksekliği, lokaliteleri ve koordinatları hakkında veriler sunulmuştur. İncelenen anıt ağaçların 5 tanesi Platanus orientalis, 3 tanesi Quercus petraea, 2 tanesi Tilia rubra subsp. caucasica, 2 tanesi Quercus robur, birer tanesi de Tilia platyhyllos, Fagus orientalis ve Carpinus betulus taksonlarına aittir. Anıt ağaçların tahmini yaşları 150- 600 yıl aralığında değişmektedir. Tilia platyhyllos incelenen anıt ağaçlar içerisindeki en yaşl, en uzun boylu ve en geniş çaplı ağaçtır.

Anahtar kelimeler: Anıt ağaç, ekoturizm Karadeniz, Ordu

\section{Monumental Trees in Ordu Province}

\section{Abstract}

In this study, the 15 monumental trees registered as natural assets in Ordu province were examined in their habitats and information regarding their features were given. Data on the species names of the monumental trees, family names, estimated ages, the diameter of the trees, height, the first branching height, localities and coordinates were presented. The monumental trees studied were Platanus orientalis (5), Quercus petraea (3), Tilia rubra subsp. caucasica (3), Quercus robur (2), Tilia platyhyllos (1), Fagus orientalis (1) and Carpinus betulus (1). The estimated age of monumental trees ranged between
150 and 600 years. Tilia platyhyllos is the oldest, tallest and widest tree in the studied monumental trees.

Key words: Monumental tree, Ordu, ecotourism, Blacksea

\section{Giriș}

Anıt ağaçlar, doğa tarihinin geçmişini yansıtmaları bakımından bilimsel bir öneme sahiptirler (Özçelik ve ark., 1998). Yaş, çap ve boy itibariyle kendi türünün alışllagelmiş ölçülerinin çok üzerindeki boyutlara sahip olan, yöre tarihinde, kültür ve folklorunda özel yeri bulunan; geçmiş ile günümüz, günümüz ile gelecek arasında iletişim sağlayabilecek uzunlukta doğal ömre sahip ağaçlar, "anıt ağaç" olarak isimlendirilmektedir (Asan,1992). Anıt ağaçlar; tarihi anıt ağaçlar, folklorik anıt ağaçlar, mistik anıt ağaçlar ve boyutsal anıt ağaçlar olmak üzere dört gruba ayrılabilir (Asan, 1992). Anıt ağaçlar hem kültürel hem de doğal miraslarımızdandır. Anıt ağaçların tespit edilmesi, koruma altına alınması ve gelecek nesillere aktarılması oldukça önemlidir. Ülkemizdeki anıt ağaçlar üzerinde çeşitli çalışmalar yapılmış ve anıt ağaçların belirlenmesi, tanıtılması ve korunmasına yönelik önemli katkılar sağlanmıştır (Asan, 1987; 1992; 2010; Kavgacl, 2002; Genç ve Güner, 2003; Palabaş Uzun ve ark., 2007; Koca 2014; Sarıbaş, 2015; Polat, 2017). Ülkemizde resmi makamlarca tescili yapılan anıt ağaç sayısının 2300 civarında olduğu bildirilmektedir (Genç ve Güner, 2003; Palabaş Uzun ve ark., 2007). Bu çalışma ile Ordu ilinde bulunan 15 anıt ağacın tanıtılması, genel özelliklerinin belirlenmesi ve ekoturizme kazandırılması amaçlanmaktadır. 


\section{Materyal ve Yöntem}

Ordu ilinde anıt ağaç olarak tescil edilmiş 15 ağaç bulundukları habitatlarda incelenmiş ve özellikleri hakkında bilgiler verilmiştir. Çalışma Nisan-Haziran 2016 tarihleri arasında gerçekleştirilmiştir. İncelenen ağaçların tür isimleri, familya isimleri, tahmini yaşları, ağaçların çapı, yüksekliği, ilk dallanma yüksekliği, lokaliteleri ve koordinatları hakkında bilgiler verilmiştir. Çap tespiti için ağaçların toprak yüzeyinden yaklaşık $1.30 \mathrm{~m}$ yükseklikteki çevresi hesaplanmıș ve elde edilen değer $\pi$ (3.14) sayısına bölünerek çap değeri hesaplanmıştır (Asan, 1991). Gövde üzerinde ilk dallanmanın olduğu yükseklik toprak yüzeyinden itibaren ölçülmüştür. Bitkilerin Türkçe isimleri Türkçe Bitki Adları Sözlüğüne (Baytop, 1994) göre belirlenmiştir. Ağaçların tahmini yaşları yöre halkı ile yapılan yüz yüze görüşmeler sonucu tahmini olarak belirlenmiştir. Ayrıca her bir ağaca ait özellikler ve açıklayıcı bilgiler arazi çalışmaları sırasında not edilmiştir.

\section{Bulgular}

Ordu ilinde bulunan bazı anıt ağaçların genel özellikleri, yaşları, Türkçe ve Latince isimleri şunlardır (Çizelge1, Şekil 1-16):

\section{Carpinus betulus L. (Betulaceae), Gürgen}

Ordu ili, Perşembe ilçesi, Çamarası Köyü sınırları içerisinde bulunan anıt ağaç yaklaşık 250 yıllıktır Ağacın çapı $3.20 \mathrm{~m}$, boyu ise $23 \mathrm{~m}$ dir. Kirazlık Evliyası adıyla anılan alan üzerinde birden fazla anıt ağacın bulunduğu Trabzon Kültür ve Tabiat Varlıklarını Koruma Kurulu'nun (KTVKBK) 06.10.199 tarih ve 3509 sayılı kararıla tescil edilmiştir. Daha sonra Samsun KTVKBK'nun 14.04.2011 tarih ve 3044 sayll kararıla kuruyan bazı ağaçların tescili kaldırılmıştır. Alanda son olarak 3 adet meşe 3 adet gürgen ağacının bulunduğu bildirilmiştir. Fakat yol yapım çalışmaları sonucunda diğer ağaçların tahrip olduğu ve yıkıldığı belirlenmiştir. Arazi çalışmalarımız sırasında sadece bir ağaç bulunabilmiştir (Çizelge 1, Şekil 1).

\section{Fagus orientalis Lipsky (Fagaceae), Doğu kayını}

Akkuş ilçesi Damyeri mahallesi mezarlığında bulunan ağaç yaklaşık 450 yıllıktır. Çapı $5 \mathrm{~m}$ olan kayın ağacının boyu $25 \mathrm{~m}$ civarındadır. Ulaşımı zor bir bölgede bulunduğu için fazla tahribe uğramamıştır. 13.01.2011 tarihinde tabiat varlığı olarak tescil edilmiştir (Çizelge 1, Şekil 2) .

\section{Quercus robur L. (Fagaceae), Saplı meşe}

Altınordu ilçesi Saraycık mahallesi sınırları içerisinde bulunan 2 adet saplı meșe ağacı Samsun Tabiat Varlıklarını Koruma Bölge Komisyonu'nun 28.08.2012 tarihinde anıt ağaç olarak tescil edilmiştir. Ağaçlar yaklaşık 250 yaşındadır. Ağaçların boyları $22 \mathrm{~m}$ ve 25 m'dir. Mahalle mezarlığında yol kenarında bulunan ağaçlar toprak kayması nedeni ile tehlike altındadır. Ağaçların önlerine bir duvar örülerek koruma altına alınması gerekmektedir. (Çizelge 1, Şekil 3a-b).

\section{Quercus petraea (Matt.) Liebl. (Fagaceae), Sapsız meşe}

Perşembe ilçesi Gündoğdu mahallesinde bulunan meşe ağacı yaklaşık 500 yaşındadır. Bir evin avlusunda bulunan anıt ağaç oldukça iyi durumdadır. Yaklaşık $30 \mathrm{~m}$ boyunda olan anıt ağaç $3 \mathrm{~m}$ çapındadır. Samsun Kültür ve Tabiat Varlıklarını Koruma Bölge Kurulu'nun 17.05.2011 gün ve 3097 sayılı kararıyla tabiat varlığı olarak tescil edilmiştir (Çizelge 1, Şekil 4).

\section{Quercus petraea (Matt.) Liebl. (Fagaceae), Sapsız meşe}

Perşembe ilçesi Yumrutaş mahallesinde yöre halkı tarafindan Sinan Dede Evliyası olarak anılan tepe üzerindeki ormanlık alanda bulunmaktadır. Alanda aynı zamanda mezarlıklar bulunmaktadır. Yaklaşık 400 yaşında olduğu söylenen meșe ağacı $20 \mathrm{~m}$ boyunda $2 \mathrm{~m}$ çapındadır. 08.04.2005 tarihinde tabiat varlığı olarak tescil edilmiştir (Çizelge 1, Şekil 5).

\section{Quercus petraea (Matt.) Liebl. (Fagaceae), Sapsız meşe}

Gülyalı ilçesi Turnasuyu mahallesinde bulunan ağaç şehir merkezine en yakın olan anıt ağaçtır. Yaklaşık 550 yıllık olduğu ifade edilen ağaç mezarlık alanda yol kenarında bulunmaktadır. Ağacın çapı $3 \mathrm{~m}$, boyu $13 \mathrm{~m}$ dir. Gövdesinin belirli bir kısmı yanmış olmasına rağmen yaprak ve meyve veren bir ağaçtır. 28.05.2005 tarihinde tabiat varlığ edilmiştir. Ağaç koruma altına alınmadığı için arazi çalışmamızdan kısa bir süre sonra 2016 yılında yıkılmıştır (Çizelge 1, Şekil 6).

\section{Platanus orientalis L. (Platanaceae), Doğu Çınarı}

Fatsa ilçesinde şehir meydanında bulunmaktadır. Merkezi bir konumda olmasına rağmen iyi korunmuștur. 30.04.1993 tarihinde tabiat varlı̆̆ olarak tescil edilmiștir. Yaklașık 500 yașında olan çınar ağacı $16 \mathrm{~m}$ boyunda ve $2 \mathrm{~m}$ çapındadır (Çizelge 1, Şekil 7). 


\section{Platanus orientalis L. (Platanaceae), Doğu Çınarı}

Ünye ilçesinde şehir meydanında bulunmaktadır. Yaklaşık 500 yaşında olduğu bilinen ağaç koruma altına alınmış ve iyi korunmuştur. 24.06.1983 tarihinde tabiat varlığı olarak tescil edilmiştir. İncelenen ağaçlar içerisinde ilk tescil edilen anıt ağaç özelliğindedir. İlçenin sembolü haline gelmiştir. Anıt olduğunu belirten tabelası bulunmaktadır. Anıt ağaç $14 \mathrm{~m}$ boyunda ve $4.60 \mathrm{~m}$ çapındadır (Çizelge 1, Şekil 8).

\section{Platanus orientalis L. (Platanaceae), Doğu Çınarı}

Fatsa ilçesinde deniz kenarına yakın bir parkta 3 anıt ağaç yan yana bulunmaktadır. Ağaçların yaklaşık 500 yıllık oldukları bilinmektedir. En uzunu $21 \mathrm{~m}$ yüksekliğinde olan ağaçların çapları da 2.75-3.25 m aralığında değişmektedir. Anıt ağaçlar 30.04.1993 tarihinde tabiat varlığı olarak tescil edilmişlerdir (Çizelge 1, Şekil 9-11).

\section{Tilia platyhyllos Scop. (Tiliaceae), Büyük Yapraklı Ihlamur}

Çatalpınar ilçesi Ortaköy mahallesinde mezarlık alan içerisinde bulunmaktadır. İyi korunmuş durumda olan anıt ağaç yaklaşık 600 yıllıktır. $32 \mathrm{~m}$ boyunda olan ağacın çapı 5 m'dir. 06.05.2006 tarihinde anıt ağaç olarak tescil edilmiştir. Ağaç üzerinde anıt ağaç olduğunu bildiren bir tabela bulunmaktadır (Çizelge 1,Şekil 12).

11. Tilia rubra DC. subsp. caucasica (Rupr.) V. Engler (Tiliaceae), Kafkas Ihlamuru

Altınordu ilçesi Efirli mahallesinde caminin bahçesinde bulunmaktadır. 14.02.2007 tarihinde tabiat varlığı olarak tescil edilmiştir Zaman zaman bakımı yapılan ağaç oldukça iyi durumdadır. $26 \mathrm{~m}$ boyunda olan ağacın 1. dallanma yüksekliği 2.10 m'dir. Anıt ağaç yaklaşık 450 yıllıktır. (Çizelge 1, Şekil 13).

12. Tilia rubra DC. subsp. caucasica (Rupr.) V. Engler (Tiliaceae), Kafkas Ihlamuru

Altınordu ilçesi Bayadı mahallesinde özel mülkiyete ait olan bir evin bahçesinde bulunmaktadır. Gövde alt kısımdan ikiye ayrılmıştır. Sağlıklı bir ağaçtır. Yaklaşık 150 yıllık olduğu söylenen ağaç $22 \mathrm{~m}$ boyundadır. 21.09.2012 tarihinde anıt ağaç olarak tescil edilmiştir. (Çizelge 1, Şekil 14).

Çizelge 1. İncelenen anıt ağaçların genel özellikleri

\begin{tabular}{|c|c|c|c|c|c|c|}
\hline Tür ismi & Türkçe isim & Yaş & Çap (m) & Boy $(\mathrm{m})$ & $\begin{array}{c}\text { 1. dallanma } \\
\text { yüksekliği }(\mathrm{m})\end{array}$ & Lokalite-Koordinat \\
\hline $\begin{array}{l}\text { Carpinus } \\
\text { betulus }\end{array}$ & Gürgen & 250 & 3.20 & 23 & 1.30 & $\begin{array}{l}\text { Ordu- Perşembe, Çamarası mah. } \\
40^{\circ} 58^{\prime} 02.26^{\prime \prime} \mathrm{N} 37^{\circ} 39^{\prime} 16.16^{\prime \prime} \mathrm{E}\end{array}$ \\
\hline $\begin{array}{c}\text { Fagus } \\
\text { orientalis }\end{array}$ & Doğu kayını & 450 & 5.00 & 25 & 2.20 & $\begin{array}{c}\text { Ordu-Akkuș, Damyeri. } \\
40^{\circ} 49^{\prime} 13.99^{\prime \prime} \text { N } 37^{\circ} 07^{\prime} 53.92^{\prime \prime} \mathrm{E}\end{array}$ \\
\hline $\begin{array}{l}\text { Quercus } \\
\text { robur }\end{array}$ & Saplı meşe & 250 & 1.80 & 22 & 2.60 & $\begin{array}{l}\text { Ordu- Altınordu, Saraycık mah } \\
40^{\circ} 55^{\prime} 54.66^{\prime \prime} \text { N } 37^{\circ} 58^{\prime} 38.75^{\prime \prime} \text { E }\end{array}$ \\
\hline $\begin{array}{l}\text { Quercus } \\
\text { robur }\end{array}$ & Saplı meșe & 250 & 1.40 & 25 & 2.80 & $\begin{array}{l}\text { Ordu- Altınordu, Saraycık mah. } \\
40^{\circ} 55^{\prime} 54.66^{\prime \prime} \text { N } 37^{\circ} 58^{\prime} 38.75^{\prime \prime} \mathrm{E}\end{array}$ \\
\hline $\begin{array}{l}\text { Quercus } \\
\text { petraea }\end{array}$ & Sapsız meşe & 500 & 3.00 & 30 & 3.00 & $\begin{array}{l}\text { Ordu- Perşembe, Gündoğdu mah. } \\
41^{\circ} 02^{\prime} 14.83^{\prime \prime} \text { N } 37^{\circ} 46^{\prime} 49.01^{\prime} \text { E }\end{array}$ \\
\hline $\begin{array}{l}\text { Quercus } \\
\text { petraea }\end{array}$ & Sapsız meşe & 400 & 2.00 & 20 & 2.20 & $\begin{array}{l}\text { Ordu- Perşembe, Yumrutaş mah. } \\
41^{\circ} 05^{\prime} 47.97^{\prime \prime} \text { N 370 } 45^{\prime} 27.15^{\prime \prime} \mathrm{E}\end{array}$ \\
\hline $\begin{array}{l}\text { Quercus } \\
\text { petraea }\end{array}$ & Sapsız meșe & 550 & 3.00 & 13 & 1.20 & $\begin{array}{l}\text { Ordu- Gülyalı,Turnasuyu mah. } \\
40^{\circ} 58^{\prime} 16.05^{\prime \prime} \text { N } 37^{\circ} 59^{\prime} 48.21^{\prime \prime} \text { E }\end{array}$ \\
\hline $\begin{array}{l}\text { Platanus } \\
\text { orientalis }\end{array}$ & Doğu çınarı & 500 & 2.00 & 16 & 1.85 & $\begin{array}{l}\text { Ordu- Fatsa, Şehir meydanı. } \\
41^{\circ} 01^{\prime} 51.07^{\prime \prime} \text { N } 37^{\circ} 30^{\prime} 00.90^{\prime \prime} \mathrm{E}\end{array}$ \\
\hline Platanus & Doğu çınarı & 500 & 4.60 & 14 & 1.00 & Ordu- Ünye, Şehir meydanı. \\
\hline orientalis & 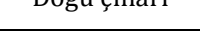 & & & 14 & 1.00 & $40^{\circ} 07^{\prime} 50.77^{\prime \prime} \mathrm{N} \quad 37^{\circ} 17^{\prime} 09.28^{\prime \prime} \mathrm{E}$ \\
\hline $\begin{array}{l}\text { Platanus } \\
\text { orientalis }\end{array}$ & Doğu çınarı & 500 & 3.10 & 18 & 4.50 & $\begin{array}{c}\text { Ordu- Fatsa, Deniz kenarl. } \\
41^{\circ} 01^{\prime} 57.17^{\prime \prime} \mathrm{N} \quad 37^{\circ} 29^{\prime} 58.72^{\prime \prime} \mathrm{E}\end{array}$ \\
\hline $\begin{array}{l}\text { Platanus } \\
\text { orientalis }\end{array}$ & Doğu çınarı & 500 & 3.25 & 21 & 3.00 & $\begin{array}{l}\text { Ordu- Fatsa, Deniz kenarı. } \\
41^{\circ} 01^{\prime} 57.17^{\prime \prime} \mathrm{N} \quad 37^{\circ} 29^{\prime} 58.72^{\prime \prime} \mathrm{E}\end{array}$ \\
\hline $\begin{array}{l}\text { Platanus } \\
\text { orientalis }\end{array}$ & Doğu çınarı & 500 & 2.75 & 20 & 4.80 & $\begin{array}{c}\text { Ordu- Fatsa, Deniz kenarı. } \\
41^{\circ} 01^{\prime} 57.17^{\prime} \text { N } 37^{\circ} 29^{\prime} 58.72^{\prime \prime} \mathrm{E}\end{array}$ \\
\hline $\begin{array}{c}\text { Tilia } \\
\text { platyhyllos }\end{array}$ & $\begin{array}{l}\text { Büyük yapraklı } \\
\text { ıhlamur }\end{array}$ & 600 & 5.00 & 32 & 1.90 & $\begin{array}{l}\text { Ordu- Çatalpınar, Ortaköy mah. } \\
40^{\circ} 82^{\prime} 16.47^{\prime \prime} \mathrm{N} 37^{\circ} 44^{\prime} 14.33^{\prime \prime} \mathrm{E}\end{array}$ \\
\hline $\begin{array}{l}\text { Tilia rubra subsp. } \\
\text { caucasica }\end{array}$ & $\begin{array}{c}\text { Kafkas } \\
\text { shlamuru }\end{array}$ & 450 & 3.40 & 26 & 2.10 & $\begin{array}{l}\text { Ordu-Altınordu, Efirli mah. } \\
41^{\circ} 00^{\prime} 38.59^{\prime \prime} \mathrm{N} 37^{\circ} 48^{\prime} 41.91^{\prime \prime} \mathrm{E}\end{array}$ \\
\hline $\begin{array}{l}\text { Tilia rubra subsp. } \\
\text { caucasica }\end{array}$ & $\begin{array}{c}\text { Kafkas } \\
\text { ıhlamuru }\end{array}$ & 150 & 2.10 & 22 & 2.70 & $\begin{array}{l}\text { Ordu- Altınordu, Bayadı mah. } \\
40^{\circ} 54^{\prime} 05.71^{\prime \prime} \mathrm{N} 37^{\circ} 53^{\prime} 36.73^{\prime \prime} \mathrm{E}\end{array}$ \\
\hline
\end{tabular}



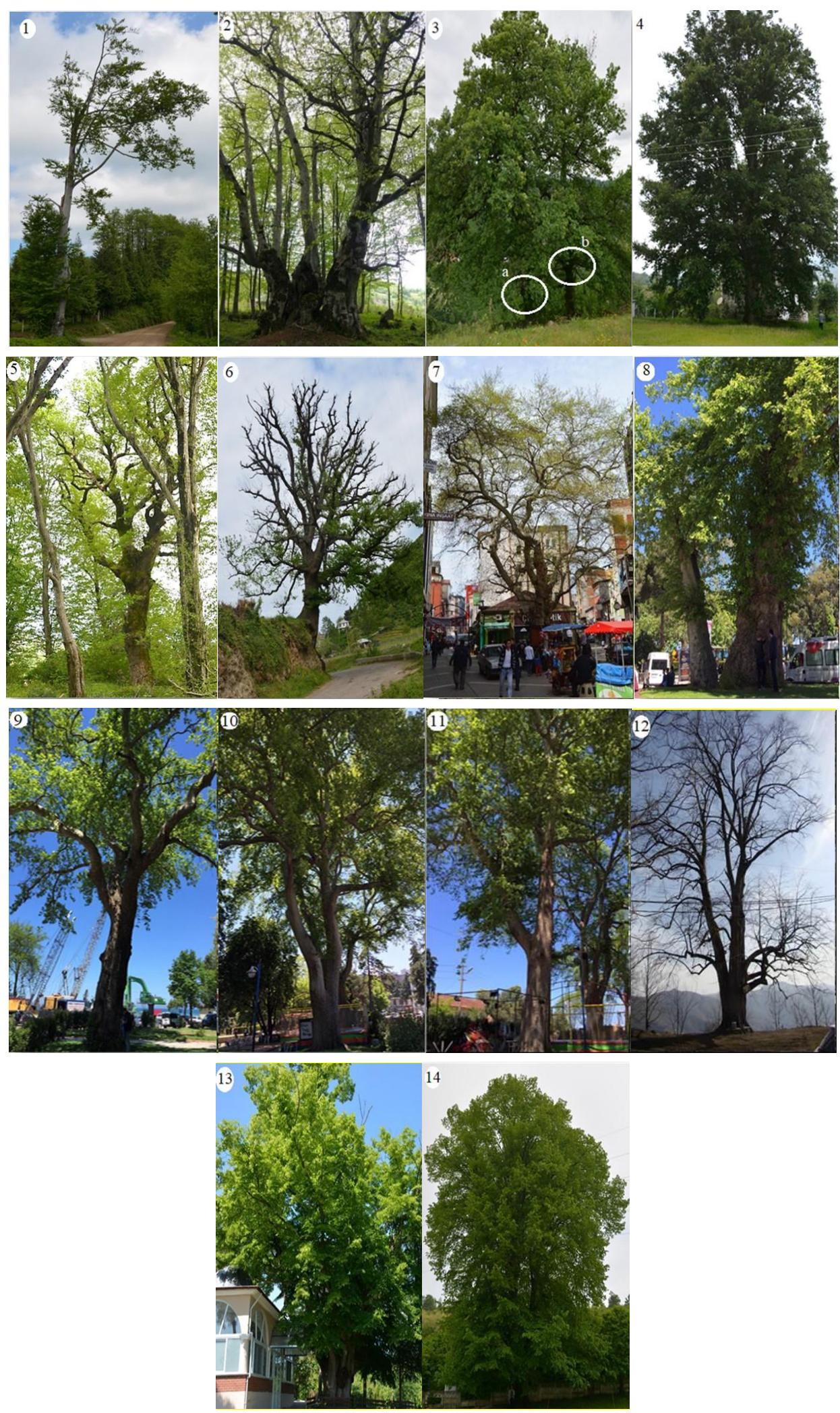

Şekil 1-14. İncelenen anıt ağaçların genel görünüșleri. 1. Carpinus betulus. 2. Fagus orientalis 3a. Quercus robur, 3b. Quercus robur, 4. Quercus petraea, 5. Quercus petraea, 6. Quercus petraea, 7. Platanus orientalis, 8. Platanus orientalis, 9. Platanus orientalis, 10. Platanus orientalis, 11. Platanus orientalis 12. Tilia platyhyllos, 13. Tilia rubra subsp. caucasica, 14. Tilia rubra subsp. caucasica 


\section{Sonuçlar ve Tartışma}

İncelediğimiz anıt ağaçların 1 tanesi 150, 3 tanesi 200-300, 9 tanesi 400-500 ve 2 tanesi de 550-600 yaş aralığındadır. Dünyanın en yaşlı ağacı ise İsveç'te keşfedilen ve yaşı 14 karbon metodu kullanılarak bulunan bir Norveç ladinidir (Picea abies (L.) Karst). "Yaşlı Tjikko" ismi verilen ağaç yaklaşık 9500 yaşındadır (Anonim, 2008). Anıt ağaçların en önemli özelliklerinden biri fiziksel büyüklüğüdür. Ancak fiziksel özellik tek başına yeterli değildir. Ağacın belirli bir yaşın üzerinde olması gerekmektedir. Bu yüzden fiziksel olarak oldukça iri ve heybetli olsalar da kavak, sögüt, kızılağaç gibi ağaç türleri gerekli doğal ömre sahip olmadıkları için anıt ağaç niteliği taşımazlar (Asan 2007). Ülkemizde en fazla anıt ağaca rastlanan türler; doğu çınarı (Platanus orientalis), Toros sediri (Cedrus libani) ve meşe (Quercus sp.) türleridir (Asan, 1987). İncelediğimiz anıt ağaçların 5 tanesi Platanus orientalis, 3 tanesi Quercus petraea, 2 tanesi Tilia rubra subsp. caucasica, 2 tanesi Quercus robur, 1 tanesi Tilia platyhyllos, 1 tanesi Fagus orientalis, 1 tanesi Carpinus betulus türüne aittir. Anıt niteliği taşıyan türlerden en yaygın olanı Platanus orientalis türüdür. Ordu ili anıt ağaçları arasında da en fazla bu türe rastlanılmıştır. Özdemir ve ark. (1986), Bayar ve ark. (2012) ve Sarıbaş (2015) yaptıkları çalışmalarda Platanus orientalis türünün anıt ağaç olarak tescil edildiğini bildirmişlerdir. Asan (2010) İstanbul'un anıt ağaçları ile yaptıkları çalışmada 215 adet Platanus orientalis bireyinin anıt ağaç niteliğinde olduğunu belirtmiştir. Bazı ağaçlar gerekli fiziksel boyutlara sahip olmasa da tanıklı ettikleri olaylardan dolayı anıtsal nitelik taşımaktadır. Bugün kutsal mekanlarda veya şehir merkezlerinde bulunan birçok anıt ağaç bu özellikleri taşımaktadır (Asan ve Uzun 1994). Anıt ağaçlar incelendiğinde; sedir, ardıç ve kayın gibi türlerin daha çok orman alanlarında tek ağaç ya da orman parçaları halinde, çınar, servi ve meşelerin ise yerleşim alanları içinde ve civarındaki kutsal mekânlarda tek başına tarihe tanıklık ettiği görülmektedir (Asan, 2010). Bu yüzden anıt ağaçlara genellikle mezarlıklar, tarihi yapılar ve kutsal mekanların bahçelerinde rastlanmaktadır. İncelediğimiz anıt ağaçların 8 tanesi mezarlık yakınında veya kutsal mekanlarda, 5 tanesi şehir meydanı ve çevresinde, 2 tanesi ise özel mülkiyet içerisinde bulunmaktadır. Ülkemizdeki anıt ağaçlar üzerinde yapılan çalışmalar anıt ağaçların belirlenmesi, tanıtılması ve korunmasına yönelik önemli katkılar sağlamış ve bu sayede anıt ağaçların tespitine yönelik çalışmalar hızlanmıştır (Asan, 1992; Güner,1994;1995;1997; Yaltırık, 1994; Boydak ve Asan, 1997; Özçelik ve ark., 1998; Tatlı ve ark. 2000; Genç ve Güner, 2003; Palabaş Uzun ve ark., 2007). Anıt ağaçlar ekolojik, sosyal ve görsel anlamda faydalar sağlayan doğal miraslarımızdır (Polat, 2017). Ancak anıt ağaçları tehdit eden pek çok faktör bulunmaktadır. Anıt ağaçların geleceğe taşınması ve yerinde korunması oldukça önemlidir (Polat, 2017). Anıt ağaçların korunmasında alınabilecek yasal önlemlerin yanında ağacın içinde bulunduğu şartların iyileştirilmesini sağlayacak teknik önlemler ve halkın bilinçlendirilmesi de dikkat edilmesi gereken konulardır (Asan, 2007). Kavgacı (2002) yaptığı çalışmada anıt ağaçların korunmasının hem ağaç hem de insan sağlığı için önemli olduğunu bu nedenle ağaç etrafında yapılacak olan insan eylemlerinin sınırlandırılması gerektiğini belirtmiştir. Araştırmacı ağacın ölümü veya zorunluluktan dolayı kesilmesi durumunda ise bu ağaçtan bilimsel bir malzeme olarak yararlanılabildiği gibi korunarak sergilenmesinin de mümkün olduğunu ifade etmiştir. Ordu il sinırları içerisinde 20 tane anıt ağaç tespit edilmiştir (Anonim, 2010). Yaptığımız çalışmalarda Ordu ili Perşembe ilçesi Çamarası Köyünde bulunduğu söylenen 3 gürgen ve 3 meșe ağacından sadece bir gürgen ağacının kaldığı diğerlerinin yol çalışması sırasında tahrip olduğu görülmüştür. $\mathrm{Bu}$ anıt ağaçların çoğu sadece tescillenmiş ama korunmaları yönünde herhangi bir çalışma yapılmamıştır. Bu ağaçların koruma altına alınması gerektiğine en güzel örnek Gülyalı ilçesi Turnasuyu mahallesinde bulunan ve arazi çalışmalarımız bittikten kısa bir süre sonra ölen meşe ağacı (Quercus petraea)'dır. Merkeze çok yakın bir yerde bulunan ağaç hem heybetli görüntüsü hem de kolay ulaşımı bakımından ekoturizm açısından en uygun anıt ağaçlardan birisi olma özelliğindeydi. Yaklaşık 6 asırlık bir tarihe tanıklık etmiş bu ağacın ölmüş olması oldukça üzüntü verici bir kayıptır. Yaptığımız bu çalışma ile ilimizde tescillenmiş doğal mirasımız olan 15 anıt ağacın genel özelliklerini ortaya koymaya ve bu ağaçlar ile ilgili farkındalık oluşturmaya çalıştık. Ayrıca çalışmanın ülkemizin anıt ağaçları envanterine katkı sağlayacağı düşüncesindeyiz.

\section{Kaynaklar}

Anonim, 2008. news.nationalgeographic..http://www. nationalgeographic.com. (Erişim tarihi: 15 Kasım, 2017). 
Anonim, 2010. Ordu taşınmaz Kültür varlıkları Envanteri. TC. Ordu Valiliği İl Kültür ve Turizm Müdürlügü.

Asan, Ü., 1987. Türkiye Ormanlarında Saptanabilen Anıt Nitelikli Ağaçların Dünya'daki Benzerleri ile Karşılaştırılması, İstanbul Üniversitesi Orman Fakültesi Dergisi Seri A, 37(2): 46- 68.

Asan, Ü., 1991. Doğal ve Kültürel Miraslarımızdan Anıt Ağaç ve Ormanlarımız. Yeşile Çerçeve, 6: 22-24.

Asan, Ü., 1992. Anıt ağaçların birey ve toplum psikolojisi üzerindeki etkileri. Yeşile Çerçeve Dergisi, 18.

Asan, Ü., Uzun, A., 1994. Marmara Bölgesindeki Doğal ve Kültürel Mirasımız: Anıt Ağaçlar. Doğal Değerlerin Korunması ve Kurumlaşma Stratejileri Ulusal Semineri.

Asan, Ü., 2007. Anıtsal Ağaçların Tanımı, Teknik Özellikleri ve Korunmaları. Kent Ağaçları ve Süs Bitkilerinde Bakım ve Budama Esasları Semineri, 157-168. İBBB Basımevi, İstanbul.

Asan, Ü., 2010. İstanbul'un Doğal Mirası Anıt Ağaçlar, İBB. Kültür Yayınları

Bayar, E., Türker, H., Genç, M., 2012. Gölhisar - Burdur Anıt Ağaçları: Göller Bölgesi Anıt Ağaç Varlığına Yeni İlaveler. Bartın Orman Fakültesi Dergisi. 14(22): 83-95.

Baytop, T., 1994. Türkçe Bitki Adları Sözlüğü. Türk Dil Kurumu Yayınları, Ya-yın No: 578, Ankara,

Boydak, M., Asan, Ü., 1997. Monumentel Trees and Forests (The Cultural and Natural Heritage of Whole mankind) XI. World Forestry Congress, 13-22 October 1997, Antalya, Turkey.

Genç, M., Güner, S.T., 2003. Göller Bölgesi'nin Anıt Ağaçları, Isparta Valiliği Özel İdare Müdürlügü, İdeal Matbaası, 231s.

Güner, A., 1994. Monumental trees of Turkey: 7. The Karaca Arboretum Magazine 2(4): 181- 186.
Güner, A., 1995. Monumental trees of Turkey: 9 Gökbulatan Findık. The Karaca Arboretum Magazine 3(2): 87-89.

Güner, A., 1997. Monumental trees of Turkey: 13 Türbeçamı. The Karaca Arboretum Magazine 4(1): 43-46.

Kavgacı, A., 2002. Türkiye'nin Anıt meşeleri ve Yeni Bir Anıt meşe (Çeçe Sultan Meşesi), İ.Ü. Orman Fakültesi Dergisi, 52(1): 133-142.

Koca, A.D., 2014. Monumental Trees in Akçakoca (Düzce, Turkey): Utilities of Natural Resources for Ecotourism. Hacettepe J. Biol. \& Chem., 42(3): 421427

Özçelik, H., Doğan, Ü., Tanrıver H, 1998. Göller yöresinden bazı abide ağaçlar. Ekoloji Çevre Dergisi, 7(26): 1317.

Özçelik, R., 2006. Mersin-Aydıncık İlçesi Anıt Dallı Servileri (Cupressus sempervirens L. var. horizontalis (Mill.) Gord.) R. Süleyman Demirel Üniversitesi, Fen Bilimleri Enstitüsü Dergisi, 10(2): 197-201.

Özdemir, Ü., Göncüoğlu, C., Tütüncü, G., Tanca, N., Tümer, A., 1986. Doğal Anıtlar. E.U. Journal of Science Fac., Ser. B, Vol. 8, 221-230

Palabaş Uzun, S., Uzun, A., Terzioğlu, S., 2007. Doğal Mirasımıza Bir Katkı: Anıt Doğu Ladini (Picea orientalis (L.). Düzce Üniversitesi Ormancıllk Dergisi. 3(2): 42-54.

Polat, Z., 2007. Doğanın mirası: Anıt Ağaçlar. Türk TarımGıda Bilim ve Teknoloji Dergisi. 5 (8): 908-916.

Sarıbaş, M., 2015. Batı Karadeniz Bölgesi'nin Kayda Girmemiş Anıt Ağaçları. Ege Üniversitesi Ziraat Fakültesi Dergisi, 52 (1):13-21.

Tatlı, A., Küçükkaraca, B., Akan, H., Çelik, H., Coşkun, F., 2000. Kütahya'nın Anıt Ağaçları, Kütahya Valiliği, Çevre Koruma Vakfı Yayını, 231s., Kütahya.

Yaltırık, F., 1994. Tarihi ve Anıtsal Nitelikte Ağaç ve Ormanlarımız, Sandoz Dergisi, 4(1):11-18. 